\title{
USO DE PSICOFÁRMACOS EM CRIANÇAS E ADOLESCENTES
}

\author{
Mateus Silvestre MOREIRA ${ }^{1}$ \\ Rodrigo Gomes de MORAIS ${ }^{1}$ \\ Edimar Agnaldo MOREIRA ${ }^{2}$ \\ Sâmara Fernandes LEITE ${ }^{3}$ \\ Claudia Cristina TEIXEIRA ${ }^{4}$ \\ Malu Emanuelle SILVA ${ }^{5}$ \\ Daniela Fernanda de FREITAS ${ }^{6}$
}

1. Discente, Faculdade de Ciências e Tecnologias de Campos gerais do Curso de Enfermagem Bacharelado;

2. Discente, Universidade Federal de Alfenas, Pós Graduação em Ecologia e Tecnologia Ambiental;

3. Enfermeira da Unidade de Terapia Intensiva Cardiovascular do Hospital Aroldo Tourinho-Montes Claros (MG).

4. Medica oncologista da Santa casa de Montes Claros - MG e da Clínica Oncovida.

5. Enfermeira da Estratégia de Saúde da Família(ESF) Viva a Vida - Bocaiúva (MG).

6. Docente, Faculdade de Ciências e Tecnologias de Campos gerais, Curso de Graduação em Farmácia Generalista e Enfermagem Bacharelado. danielaffreitas@bol.com.br

Recebido em: 07/10/2014 - Aprovado em: 18/09/2014 - Disponibilizado em: 15/12/2014

Resumo. Buscou-se com este trabalho verificar, a eficácia, as indicações e as contra-indicações da utilização de psicofármacos em crianças e adolescentes. Para tanto, utilizou-se de um levantamento bibliográfico em revistas, livros e artigos publicados na Internet, por meio dos quais pode-se concluir que: 1) o profissional da área de saúde deve entender a categoria farmacológica de cada medicamento, suas indicações, contra-indicações, interações medicamentosas e efeitos adversos; 2) a escolha e o início da intervenção medicamentosa devem ser baseados na história do paciente, na situação clínica atual e no plano de tratamento; 3) o emprego de psicofármacos em crianças e adolescentes deve visar o quadro sintomatológico e sindrômico; 4) As drogas psicoativas mais utilizadas em crianças e adolescentes são: A clomipramina, a fluoxetina, a paroxetina, os inibidores da monoamino-oxidase metilfenidato, Bupropiona, desipramina, haloperidol, dentre outros; 5) Em crianças e adolescentes, a associação de psicofármacos entre si ou com medicamentos para problemas clínicos requer cautela. 6) a psicoterapia com crianças e adolescentes em geral é mais direta e ativa do que costuma ser com adultos.

Palavras-chave: Psicofármacos. Adolescência. Infância. Drogas. Psicoterapia.

Abstract. We tried this experiment to verify the efficacy, indications and contraindications for the use of psychotropic drugs in children and adolescents. For this purpose, is a literature in journals, books and articles published on the Internet, through which one can conclude that: 1) the health care professional must understand the pharmacological class of each drug, its indications, contraindications, drug interactions and adverse effects, 2) the selection and initiation of drug 
intervention should be based on patient history, the current clinical situation and treatment plan, 3) the use of psychotropic drugs in children and adolescents should aim to symptomatology and syndromic; 4) The most widely used psychoactive drug in children and adolescents are: clomipramine, fluoxetine, paroxetine, inhibitors of monoamine oxidase methylphenidate, bupropion, desipramine, haloperidol, among others, 5) In children and adolescents The association of psychotropic drugs among themselves or with drugs for clinical problems requires caution. 6) psychotherapy with children and adolescents in general is more direct and active than it used to be with adults.

Keywords: Pharmacotherapy. Adolescence. Childhood. Drugs. Psychotherapy.

\section{INTRODUÇÃO}

O uso de medicamentos para tratar transtornos psiquiátricos costuma ser fundamental para a abordagem de um tratamento bem sucedido, que também pode incluir outros tipos de intervenções, como a psicoterapia ou as terapias comportamentais. À medida que o conhecimento sobre a biologia do funcionamento cerebral normal ou anormal cresce, a prática da psicofarmacologia clínica continua a evoluir quanto a seus objetivos e efetividade. Os envolvidos na prescrição e no acompanhamento clínico de tratamentos com medicamentos psiquiátricos devem estar atualizados em relação à pesquisa, inclusive sobre o lançamento de novos agentes, demonstração de outras indicações para agentes existentes e a identificação e o tratamento de efeitos adversos relacionados aos mesmos(MARI ET AL., 2005).

Segundo Kaplan e Sadock (2007), a prática da farmacoterapia em psiquiatria não deve ser simplificada demais - por exemplo, não deve ser reduzido à abordagem do tipo um diagnóstico, um medicamento. Muitas variáveis afetam essa prática, incluindo a seleção e a administração dos medicamentos, o significado psicodinâmico para o paciente e as influências da família e do ambiente.

De acordo com estes autores, alguns pacientes podem considerar a medicação como uma violência. Assim, o paciente, seus parentes e a equipe de enfermagem devem ser instruídos sobre as razões para o tratamento medicamentoso, bem como sobre os benefícios esperados e os riscos potenciais.

O questionamento do uso de psicofármacos tem sido assunto desde 1950, quando o primeiro neuroléptico começou a ser utilizado. Mas na pós-modernidade este tema tem tomado as páginas de jornal e revistas, graças ao avanço na tecnologia das indústrias farmacêuticas.

Apesar das intensas campanhas de divulgação e promoção de novos fármacos, continuam a ser muito escasso os dados acerca dos efeitos a longo-prazo deste tipo de 
medicação. Estudos recentes trazem revelações preocupantes acerca da utilização de psicofármacos em crianças e adolescentes (BRASIL, 2000).

São muitas as possibilidades de transtornos mentais nessa fase da vida, mas todas as situações devem ser muito bem avaliadas antes de se fechar um diagnóstico, principalmente na adolescência. Além das dificuldades pessoais dos adolescentes e de sua intensa modificação corporal e mental, o que por si só já pode gerar comportamentos e sentimentos de inadequação, suas atitudes podem ainda refletir problemáticas familiares. No entanto, Candiani (2009) relata que é cada vez maior o uso de psicofármacos em crianças e adolescentes, sendo indiscutível a eficácia destes na atenuação do sofrimento dos pacientes com transtornos mentais.

Neste sentido, este trabalho trata de tais polêmicas, abordando inicialmente a classificação dos medicamentos utilizados para tratar transtornos psiquiátricos, as diretrizes clínicas para utilização dos psicofármacos; a questão do tratamento com combinações medicamentosas; para, em seguida, tecer considerações especiais quanto ao tratamento em crianças e adolescentes.

\section{Transtornos psiquiátricos em crianças e adolescentes}

A Adolescência é o período do desenvolvimento humano que marca a transição entre a infância e a idade adulta. Esta é uma etapa de mudança dramática do ponto de vista social, cognitivo e físico que pode aumentar a vulnerabilidade aos distúrbios psicológicos e psicofisiológicos.

Segundo Galvão e Abuchaim (2001, p.1),

"A Adolescência é um período de intensas atividades e transformações na vida mental do indivíduo, o que, por si só, leva a diversas manifestações de comportamento que podem ser interpretadas por leigos como sendo doença. Assim sendo, muitas das manifestações ditas normais da adolescência podem se confundir com doenças mentais ou comportamentos inadequados".

$\mathrm{Na}$ adolescência, o indivíduo está descobrindo o que é ser adulto, mas não está preparado para assumir as responsabilidades de ser adulto. Neste contexto, ele procura exemplos para construir seu caráter e seu comportamento, seja nas pessoas que estão mais próximas, em ídolos ou artistas (FEB, 2003).

Nesta fase, nota-se, a busca intensa da própria identidade, muitas das vezes esta busca faz com que ocorram conflitos entre os 
adolescentes e seus pais. No entanto, percebe-se que os mesmos ainda não são capazes de viver esta separação, o que gera um sentimento de medo e um intenso conflito em seus sentimentos. Neste contexto, o uso de drogas pode constituir-se tanto em um simples comportamento de experimentação da vida como um caso de dependência. Portanto, devese avaliar bem o comportamento de um adolescente, antes de se garantir a existência ou não de um transtorno mental(GALVÃO, ABUCHAIM, 2001).

Dentre estes transtornos mentais podese citar: reações de ansiedade, a depressão, o suicídio, a esquizofrenia, a breve reação de psicose e os distúrbios de alimentação, tais como anorexia nervosa e a bulimia.

\section{Reações de Ansiedade}

Segundo Paulon (2008), um adolescente com uma reação aguda de ansiedade sente um medo repentino, como se algo ruim estivesse para acontecer, bem como ter dificuldades para adormecer, e o sono em si pode ser limitado e agitado, talvez com pesadelos ou sonambulismo.

A ansiedade deve ser tratada antes de se tornar crônica e antes que as reações do indivíduo - retraimento psicológico, dificuldade no trabalho, escolar ou persistência de sintomas físicos como dores, diarréia, falta de ar ou fadiga - tornem-se uma forma de viver (BATISTA,OLIVEIRA, 2005).

\section{Transtornos do Humor e Depressão}

Os transtornos do humor ocorrem em crianças de todas as idades, consistindo de padrões persistentes de alteração de humor, redução de prazer na realização de atividades, nos esportes, nas amizades e até na escola; além de sentimento de desvalia em geral (KAPLAN; SADOCK, 2007).

Dois critérios para transtorno do humor em crianças e adolescentes são as alterações de humor, como depressão ou euforia e a irritabilidade.

Apesar de os critérios de diagnósticos para transtornos do humor (APA, 1994), na revisão do texto da quarta edição do manual diagnóstico e estatístico de transtornos mentais, serem quase idênticos em todas as faixas etárias, a expressão da perturbação do humor varia na criança de acordo com sua idade. As crianças menores com depressão em geral exibem sintomas que aparecem com menor frequência à medida que crescem, incluindo alucinações auditivas congruentes com o humor, queixas somáticas, aparência triste, isolamento e baixa autoestima. Os sintomas que aparecem com maior frequência na adolescência tardia do que em crianças mais novas são anedonia, lentidão psicomotora 
grave, delírios e desesperança. Sintomas que aparecem com a mesma frequência, independentemente da idade e do estágio do desenvolvimento, incluem ideação suicida, humor deprimido ou irritado, insônia e redução da capacidade de concentração.

Os transtornos depressivos e bipolar tipo I em geral são episódicos, embora seu início possa ser insidioso. Episódios maníacos são raros em crianças pré-púberes, mas bastante comuns entre adolescentes. $\mathrm{O}$ transtorno de déficit de atenção/hiperatividade (TDAH), o transtorno desafiador de oposição e os transtornos de conduta podem ocorrer em crianças que mais tarde apresentam depressão (KAPLAN; SADOCK, 2007).

De acordo com Lima (2004), o primeiro estudo que ligou a depressão infantil à condição depressiva maior do adulto foi o do psiquiatra Spitz, que descreveu a síndrome de depressão anaclítica, onde as crianças separadas das mães e que eram colocadas em creches apresentavam choro, isolamento, retardo do desenvolvimento psicomotor, reação lenta, retardo do movimento, e algumas apresentavam estupor e perda do apetite. Ele postulava que o mais importante na etiologia era a perda do objeto amado. No entanto, sofreu uma série de críticas, particularmente com relação à sugestão de que a depressão anaclítica levava a um severo retardo do desenvolvimento. As críticas foram também em relação à metodologia empregada por ele. Apesar disso, o conceito de depressão anaclítica persiste até hoje. $\mathrm{O}$ renomado psiquiatra relatou o caso de uma criança de 3 meses de uma instituição que, ao chegar à idade de 8 meses, mostrou sintomas de depressão anaclítica com quadro clínico completo: choramingo, isolamento, apatia, perda de peso e distúrbio do sono.

Apesar de inexistir uma definição consensual acerca da depressão infantil, podese afirmar que se trata de uma perturbação orgânica que envolve variáveis biológicas, psicológicas e sociais. Do ponto de vista biológico, a depressão é encarada como uma possível disfunção dos neurotransmissores devido à herança genética, a anormalidades e/ou falhas em áreas cerebrais específicas(ANDRIOLA; CAVALCANTE, 1999).

Trata-se da depressão classificada como endógena, ou seja, aquela geneticamente transmitida. Desde a perspectiva psicológica, a depressão pode estar associada a algum aspecto comprometido da personalidade, baixa autoestima e autoconfiança. No âmbito social, a depressão pode ser vista como uma falta de adaptação ou um apelo de socorro, bem como uma possível consequência da violentação de mecanismos culturais, familiar, escolar, etc. As variáveis psicológicas e sociais caracterizam a depressão classificada como exógena, ou seja, a que é resultante de problemas psicológicos e/ou 
ambientais (ANDRIOLA; CAVALCANTE, 1999).

De acordo com a APA (1994), a depressão infantil é semelhante a depressão no adulto, de forma que os mesmos critérios de diagnósticos de depressão no adulto podem ser utilizados para avaliar a depressão na criança. Segundo esse manual, os sintomas de depressão são: humor deprimido na maior parte do dia, desinteresse nas atividades diárias, alteração de sono e apetite, falta de energia, alteração na atividade motora, sentimento de inutilidade, dificuldade para se concentrar, pensamentos ou tentativas de suicídio.

Um estudo da Organização Mundial de Saúde (OMS apud LEITE, 2002), demonstra que $20 \%$ das crianças e adolescentes apresentam sintomas da depressão, como irritabilidade ou apatia e desânimo. Dentro da realidade brasileira, esse número cai para $10 \%$ conforme o psiquiatra gaúcho Salvador Célia, presidente do Departamento de Saúde Mental da Sociedade Brasileira de Pediatria, afirma, porém, que se não houver intervenção médica, essas crianças são fortes candidatos a tornaremse adultos depressivos pelo resto da vida.

De acordo com Weller e Weller (1992, p.19),

"Depressão é um transtorno episódico, e os marcadores biológicos são classificados como marcadores de traço ou estado. Os marcadores de estado são positivos ou anormais durante o episódio e retornam ao normal em algum ponto durante ou após a recuperação"

Giancaterino (2008) relata que a rotina que as crianças têm a cumprir pode ser um desgaste não apenas físico, mas também mental, que começa desde cedo a exigir demais de si mesmo. Nesse sentido, ressalta-se que o excesso de atividades é um dos principais causadores do stress, na classe média e na classe menos favorecidas existem muitas situações desgastantes como: trabalhar para ajudar os pais, cuidar dos irmãos menores, irem para a escola com fome, ter que tirar boas notas sem contar com ninguém para ajudar nas tarefas escolares e vários outros fatores que acarretam o stress, que pode culminar na depressão infantil.

Segundo este mesmo autor, crianças deprimidas são classificadas como menos populares por seus pares e menos socialmente competentes por seus professores. Não está claro se déficits nas habilidades sociais, seguem-se ou precedem a depressão.

Segundo Mora (2004), a família exerce grande influência na depressão infantil. A criança desde o ventre materno até os três anos desenvolve todos os elementos básicos com que mais tarde vai construir sua vida; sentimentos, linguagem, afetos, hábitos, motivações. O apego com que a mãe e o filho se impregnam mutuamente é o veículo de uma integração social e pessoal adequada da criança. Os apegos 
inseguros podem gerar dificuldades de conduta e também depressão, assim como o apego seguro é uma boa maneira de criá-la.

Assim Mora, 2004, relata que " $a$ depressão materna aparece claramente definida como um dos fatores de risco associados ao desencadeamento da depressão na criança. Também é indispensável para o desenvolvimento saudável da criança uma boa relação com o pai".

Apesar de extremamente importante do ponto de vista preventivo, os estudos com crianças em idade pré escolar são ainda mais escassos em nossa realidade. A taxa de prevalência encontrada em crianças de 5 e 6 anos no estudo de Andriola e Cavalcante (1999) foi de $3,9 \%$, não revelando diferenças significativas em relação ao gênero. Estudos em fases iniciais da infância são muito relevantes, uma vez que se os sintomas depressivos não forem identificados podem causar uma série de dificuldades como a baixa autoestima, queda no rendimento escolar e problemas na interação social, no futuro.

Cândida (2005) apresentou em seu trabalho de estudo populacional que mostrou que cerca de $20 \%$ das crianças e adolescentes com idade entre nove e dezessete anos têm algum transtorno mental diagnosticável. Em relação à depressão especificamente, estima-se que a doença atinja, nos Estados Unidos, 0,9\% das crianças em idade pré-escolar, 1,9\% em idade escolar e 4,7\% dos adolescentes.

Estudos epidemiológicos brasileiros(BIR; DUARTE, 2002; MENEZES; MELO, 2010) têm revelado prevalência de desordens psiquiátricas de $10 \%$ a $20 \%$, no grupo etário entre 5 e 14 anos. Outros estudos sobre depressão também foram realizados, destacando-se o de Caetano (2009) que relatou que a depressão infantil atinge oito em cada cem meninos e meninas. Fatores genéticos e ambientais (como viver em meio a conflitos, brigas e violência) favorecem o surgimento da doença, que pode ser desencadeada por luto, separação dos pais, dificuldades de adaptação. Sem tratamento, ela compromete o desenvolvimento, prejudicando a capacidade cognitiva e a estruturação da personalidade. $\mathrm{Na}$ adolescência pode levar a comportamentos de risco, como o uso de drogas, e a exposição a situações de perigo.

A depressão tem tratamento, com sucesso em mais ou menos $80 \%$ dos casos. No entanto, metade das pessoas que sofrem de depressão não procura tratamento, o que leva a doença a ser a principal causa dos suicídios (MORA, 2004).

\section{Suicídio}

Kaplan e Sadock (2007) relataram em seu estudo que o suicídio é a segunda maior causa de morte entre adolescentes. Muitas internações resultam de ideação ou 
comportamento suicida. Este comportamento é o caminho final comum para inúmeros transtornos, e sua alta incidência reflete psicopatologia grave.

Segundo os estudos de Cândida (2005), a partir dos 15 anos o índice de suicídios é frequente entre adolescentes. As mulheres têm mais probabilidade do que os homens de usar métodos passivos (ingestão de drogas e venenos) de suicídio. Entre ambos os sexos, armas de fogo ou explosivos respondem pelo número de suicídios efetivados, enquanto drogas e envenenamentos respondem pelo maior número de tentativas. Os eventos desencadeadores incluem o rompimento ou ameaça de término de romance; gravidez, fracasso escolar, conflitos com pais, rejeição por parte de um amigo, ser apreendido num ato proibido ou delinquente.

Segundo Reis e Figueira (2002), adolescentes com pensamentos e comportamentos suicidas persistentes, tentativa anterior de suicídio, depressão, baixa autoestima, solidão e pessimismo constituem uma população com alto risco para uma tentativa de suicídio fatal.

Cândida (2005) salienta que os adolescentes que tentam suicídio têm uma longa história de instabilidade familiar progressiva e discórdia, tem menos amigos íntimos, mas com relacionamentos mais intensos. Ao falarem de suicídio, os adolescentes estão transmitindo uma mensagem de que alguma coisa está errada e que eles precisam de ajuda, ainda que não tenham seriamente a intenção de se suicidar. Assim, segundo Cândida (2005), existe alguns sinais que podem alertar o observador cuidadoso para a possibilidade de um eventual suicídio: ânimo de constante depressão ou desespero; distúrbios na alimentação e no sono; piora do desempenho escolar; afastamento social gradual e maior isolamento dos outros; rompimento de comunicação com pais ou outras pessoas importantes na vida do jovem; tentativas anteriores de suicídio; comportamento descuidado, autodestrutivo e atípico; comentários como "queria morrer ou viver para que?" Indagações sobre as propriedades letais de drogas, venenos ou armas; acontecimentos estressantes demais na vida.

\section{Transtorno Bipolar I}

O transtorno bipolar I está sendo diagnosticado com frequência crescente em crianças pré-púberes, levando-se em consideração o fato de que episódios maníacos "clássicos" são incomuns neste grupo etário, mesmo quando os sintomas depressivos já tenham se manifestado. Uma vez que prépúberes com manifestações de depressão e mania ou hipomania em geral exibem ciclos de humor, permanece controverso se realmente 
satisfazem os critérios diagnósticos para transtorno bipolar. Esses episódios maníacos atípicos são, por vezes, associados à história familiar de transtorno bipolar I clássico (KAPLAN; SADOCK, 2007).

Características de alterações no humor e no comportamento incluem extrema variabilidade do estado de espírito, comportamento agressivo intermitente, altos graus de distratibilidade e baixa duração da atenção. Esses aspectos não costumam ser claramente episódicos, mas mostrar flutuações, e parecem ser menos responsivos aos estabilizadores de humor.

Segundo Del Porto e Versiani (2005), crianças com episódios hipomaníacos atípicos repetidamente têm história de transtorno de déficit de atenção/hiperatividade (TDAH) grave, tornando o diagnóstico de transtorno bipolar mais complicado. Em geral, famílias com muitos parentes com TDAH não tem história familiar indicando aumento da taxa de transtorno bipolar I. O grupo de crianças portadoras de transtorno bipolar I apresenta funcionamento pobre, necessita de hospitalização frequentemente, exibe sintomas de depressão e tem história de TDAH.

\section{Transtorno de déficit de atenção/hiperatividade (TDAH)}

O transtorno de déficit de atenção/hiperatividade (TDAH) é o distúrbio do neurodesenvolvimento mais comum na infância. A apresentação clínica do TDAH compreende três categorias principais de sintomas - desatenção, impulsividade e hiperatividade - que se manifestam em ambientes diferentes e causam comprometimento funcional. Sabe-se também que o TDAH começa no início da vida e pode persistir na adolescência e idade adulta. A prevalência citada em diferentes estudos variou de acordo com a faixa etária da amostra e os critérios usados. A prevalência tradicionalmente mencionada é de 3 a $5 \%$ das crianças em idade escolar. Porém, é evidente que os estudos mais recentes encontraram prevalência mais alta, e os estudos epidemiológicos mais rigorosos definiram taxas de 4 a 12\% da população geral de crianças de 6 a 12 anos de idade(SILVA, 2003).

Seja qual for a população estudada, o TDAH é diagnosticado com maior frequência em meninos que em meninas(WAJNSZTEJN,2006). Segundo a APA (1995) apud SÁNCHEZ (2004), classificou os transtornos de déficit de atenção/hiperatividade junto com os transtornos de déficit de atenção e de comportamento disruptivo incluídos nos transtornos geralmente diagnosticados pela primeira vez na infância ou na adolescência. Trata-se de um padrão de conduta apresentado por crianças e 
adolescentes relacionados com dificuldades no desenvolvimento da manutenção da atenção, no controle dos impulsos, assim como na regulação da conduta motora em resposta às demandas da situação.

O TDAH é chamado, às vezes, de DDA (Distúrbios do Déficit de atenção). O déficit de atenção fica particularmente claro quando se pede à criança que controle seu comportamento. O problema não está tanto na falta de atenção em si, mas na rápida queda da capacidade de prestar atenção contínua (ROTHENBERGER; BANASCHEWSKI, 2005).

Segundo a Liga de Neurocirurgia Sistema Nervoso (2005), em muitos casos, o transtorno acompanha o individuo na vida adulta, embora os sintomas sejam mais brandos quando comparados aos das crianças. No Transtorno de Déficit de Atenção Hiperatividade ocomprometimento não é só social, existe uma perda na aprendizagem significativa, muitos chegam na adolescência sem saber ler, mal saberão escrever, e foram passadas de ano não por conhecimento, mas por influência os pais, ou pela lei que algumas vezes comete enganos.

Maluf (2005) relatou que o TDAH é uma síndrome que, quando diagnosticada cedo e tratada corretamente por profissionais, pode fazer parte da vida da criança sem causar sérios problemas em seu dia-a-dia.

\section{Esquizofrenia na Infância e Adolescência}

É caracterizada por pensamento desordenado, distorções da realidade ou falta de contato com a realidade, a capacidade limitada para estabelecer relações significativas com os outros; e pouco controle emocional. É sem dúvida, o distúrbio psicótico que ocorre com maior frequência. Sua incidência aumenta drasticamente a partir dos 15 anos e atinge um pico durante o final da adolescência e início da fase adulta, estabilizando-se próximo ao final da terceira décadA (CÂNDIDA, 2005).

Segundo Kaplan e Sadock (2007), a esquizofrenia pode ser identificada pela falta de fala do jovem que se torna afetada, desconectada ou mesmo incoerente, com expressões faciais ou movimentos esquisitos, distraídos, retraídos ou confusos com reações emocionais impróprias, alucinações e ilusões intensas, bizarras que também podem estar presentes.

Estes mesmos autores relataram que, fatores biológicos e hereditários amiúde desempenham papel importante no desenvolvimento desta doença. Mas, pode ser mais preciso falar em herança de uma vulnerabilidade maior à esquizofrenia do que em herdar esquizofrenia em si. Indivíduos vulneráveis têm mais probabilidade de desenvolver a doença ou de sofrer recaídas depois do tratamento, se suas famílias foram 
caracterizadas por altos níveis de stress, a manifestação de emoções negativas e o comportamento nos padrões de comunicação. Os autores acreditam, ainda, que a esquizofrenia esteja por trás do suicídio com mais frequência do que os transtornos do humor maiores.

\section{Psicose Reativa Breve}

Segundo Mari et al. (2005), é importante distinguir entre episódios psicóticos breves e esquizofrenia. Embora durante os episódios o indivíduo possa exibir alguns sintomas psicóticos, repentinos e breves, tais como incoerência, associações ou comportamentos desorganizados, ilusões ou alucinações, que costumam aparecer logo depois de um estressor psicossocial severo e reconhecível, como a perda de um ente querido ou um acontecimento que ameace a vida. Há perturbação emocional, manifestada por rápidas oscilações no humor, geralmente entre depressão e ansiedade. Os autores relatam ainda, que a psicose reativa breve pode ser acompanhada por sentimentos de leve depressão ou perda da autoestima.

\section{Perturbações na Alimentação}

Ao se estabilizar o crescimento, o adolescente corrigirá seu peso com uma dieta.
Mas em certos casos, a alimentação excessiva pode levar a séria obesidade e, em outros casos, a dieta extrema e prolongada pode levar a sérios graus de perda de peso que ameaçam a vida, conhecida como anorexia nervosa, mais provável de acontecer durante a adolescência, sendo muito mais comum em mulheres. A anorexia é uma condição extremamente desconcertante porque o adolescente tem uma percepção muito distorcida de seu corpo. Os fatores biológicos podem desempenhar algum papel, mas os psicológicos parecem ser de importância fundamental (KAPLAN;SADOCK, 2007).

Segundo Mari et al. (2005), os jovens anoréxicos sentem que foram mimados e impedidos de conduzir suas vidas, além de ter sido incapazes de formar uma identidade pessoal forte. Talvez como reação, eles exibam uma necessidade de controlar cada aspecto de suas vidas, principalmente as funções corporais.

Já a bulimia, que de acordo com estes autores, combina elementos tanto da anorexia quanto da obesidade, é a ingestão excessiva de alimentos alternada com sua eliminação, através do vômito auto-induzido ou uso excessivo de laxantes. Adolescentes bulímicos têm medo de não conseguir romper com esse padrão de alimentação e relatam um estado depressivo e pensamentos auto-depreciativos após a ingestão excessiva de comida. 


\section{Transtornos do uso de substâncias psicoativas}

O uso de drogas, é um tipo de alteração de comportamento bastante visto na adolescência. A dependência de drogas, que é o transtorno mais grave desse grupo, manifesta-se pelo uso da substância associado a uma necessidade intensa de ter a droga, ausência de prazer nas atividades sem a droga e busca incessante da droga, muitas vezes envolvendose em situações ilegais ou de risco para se conseguir a mesma (roubo e tráfico)(GALVÃO; ABUCHAIM,2001).

\section{Transtornos de conduta}

Segundo Galvão e Abuchaim (2001), os transtornos de conduta caracterizam-se por comportamentos repetitivos de contrariedade a normas e padrões sociais, conduta agressiva, desafiadora, constituindo-se em atitudes graves.

Geralmente, os adolescentes envolvemse em situações de ilegalidade e violações do direito de outras pessoas, tais como roubos, destruição de patrimônio alheio, brigas, crueldade e desobediência intensa como algumas das manifestações.

Ramos et al. (2006) chamam de tratamento biológico as intervenções que envolvem o uso de drogas ou outros procedimentos que atuam diretamente no organismo, em particular no sistema nervoso central, como a eletroconvulsoterapia.

Os numerosos agentes farmacológicos utilizados para tratar transtornos psiquiátricos são designados por três termos gerais que são usados de forma intercambiável, segundo Kaplan e Sadock (2007): medicamentos psicotrópicos, medicamentos psicoativos e medicamentos psicoterapêuticos.

Mari et al. (2005) relataram que os agentes farmacológicos utilizados para tratar transtornos psiquiátricos eram divididos em quatro categorias: 1) antipsicóticos, ou neurolépticos, utilizados para tratar psicoses; 2) antidepressivos, utilizados para se tratar depressão; 3) antimaníacos, ou estabilizadores do humor, utilizados para tratar transtorno bipolar; 4) agentes antiansiedade ou ansiolíticos, utilizados para tratar estados ansiosos (os quais eram também eficientes como hipnóticos em doses elevadas). Hoje, contudo, esta divisão é menos válida do que foi no passado pelas seguintes razões:

1. Vários medicamentos de uma classe são utilizados para tratar transtornos para os quais antes eram indicados fármacos de outra classe. Por exemplo, muitos antidepressivos são empregados em casos de transtornos de ansiedade, e alguns ansiolíticos são utilizados no tratamento de psicose, 
transtornos depressivos e transtornos bipolares.

2. Agentes de todas as quatro categorias são utilizados para tratar condições que antes não recebiam atenção medicamentosa, como transtornos da alimentação, transtorno de pânico e transtornos do controle dos impulsos.

3. Drogas como clonidina (Atensina), propanolol (Inderal), Verapamil (Dilacoron) e gabapentina (Neurotin) que podem tratar uma série de transtornos psiquiátricos de forma efetiva não se encaixam com facilidade na classificação tradicional de medicamentos.

4. Alguns termos descritivos psicofarmacológicos se sobrepõem em significado. Por exemplo, os ansiolíticos reduzem a ansiedade, os sedativos produzem um efeito calmante ou relaxante e os hipnóticos, sono. Contudo, a maioria dos ansiolíticos atua como sedativos e, em doses elevadas, podem ser utilizados como hipnóticos, e todos estes podem ser utilizados para sedação diurna em baixas doses.

Por essas razões, o profissional da área de saúde, principalmente os médicos, devem entender a categoria farmacológica de cada medicamento, suas indicações, contraindicações, interações medicamentosas e efeitos adversos.

\section{Diretrizes clínicas para a escolha do medicamento}

Segundo Kaplan e Sadock (2007), os médicos que praticam psicofarmacologia clínica necessitam de capacidade tanto de diagnosticadores como de psicoterapeutas, conhecimento dos medicamentos disponíveis e capacidade de planejar um regime farmacoterapêutico.

A escolha e o início da intervenção medicamentosa, segundo Mari et al. (2005), devem ser baseados na história do paciente, na situação clínica atual e no plano de tratamento. Os psiquiatras devem conhecer o propósito ou o objetivo do ensaio com o medicamento, o período em que o mesmo medicamento precisa ser administrado para avaliar sua eficácia, a abordagem a ser tomada para se reduzir quaisquer possíveis efeitos adversos, estratégias medicamentosas alternativas a serem utilizadas caso a atual falhe e as indicações para a manutenção do regime de longo prazo. 
Segundo ensinamentos de Ramos et al. (2006), os dois primeiros passos na escolha do tratamento medicamentoso, o diagnóstico e a identificação dos sintomas-alvo, devem ser preferencialmente realizados quando o paciente estiver livre de medicação para uma a duas semanas. Este estado deve incluir também a ausência de medicação para o sono (como os hipnóticos), em vista da qualidade do sono poder ser um importante guia para o diagnóstico e um sintoma-alvo. Se o paciente está hospitalizado, contudo, razões de segurança podem tornar difícil ou mesmo impossível conseguir um período livre de medicação.

Deve-se dar atenção não só aos medicamentos administrados no momento, mas também aos que foram interrompidos, que poderiam estar produzindo sintomas de abstinência. Uma exceção a essa prática ocorre quando se está ingerindo uma dosagem inadequada de um medicamento que, em outros momentos seria a mais apropriada. Nesses casos, Ramos et al. (2006) ressaltam que o psiquiatra pode decidir continuar com o medicamento, administrando-o em uma dose mais alta para completar um ensaio terapêutico adequado.

Segundo Rocha et al. (2004), ao decidir qual psicofármaco usar em determinado paciente, deve-se levar em consideração dois fatores igualmente importantes e comumente interligados: o diagnóstico e os sintomas-alvo. É importante fazer um diagnóstico preciso e também identificar e quantificar os sintomasalvo. Estes devem ser graves o suficiente a ponto de interferir no funcionamento e no desenvolvimento do paciente.

Em alguns casos, continuam os autores, esta decisão é facilitada, pois a mesma medicação é efetiva tanto na patologia de base como nos sintomas-alvo. Por exemplo, os antipsicóticos são utilizados para tratar tanto a esquizofrenia como os seus sintomas-alvo (alucinações, delírios, distúrbios do pensamento). $\mathrm{O}$ mesmo não ocorre com o sintoma hiperatividade, presente em vários transtornos psiquiátricos. O psiquiatra deve fazer o diagnóstico de transtorno de déficit de atenção/hiperatividade antes de iniciar o tratamento com metilfenidato. $\mathrm{O}$ uso dessa droga em um paciente com esquizofrenia em remissão, transtorno bipolar ou com um quadro borderline pode desencadear sintomas psicóticos.

Kaplan e Sadock (2007) enfatizam que a escolha do medicamento e de intervenções nãomedicamentosas deve ser baseada na revisão cuidadosa e completa de todos os problemas e recursos do paciente. Deixar de diagnosticar uma condição tratável é uma razão comum de resultados clínicos insatisfatórios. 


\section{A importância do diagnostico}

Segundo Brasil (2000), a investigação clínica da criança tem suas particularidades. Uma avaliação adequada oferece condições para o diagnóstico inicial e para o encaminhamento do caso. Nela, o psiquiatra precisa levar em conta variáveis determinantes para se chegar a uma formulação diagnóstica; deve ir além da queixa dos pais e da história da criança contada por eles. Nem sempre o motivo da consulta e os dados de anamnese são coerentes entre si e com os obtidos no encontro com a criança ou adolescente. Na anamnese da criança deve-se levar em conta o contexto familiar e social; realizar seu exame psíquico; detectar áreas saudáveis de seu funcionamento; o grau de seu sofrimento psíquico ou o prejuízo nas áreas comprometidas; sua idade e seu desenvolvimento motor, cognitivo e emocional.

Rocha et al. (2004) salientaram que deve-se obter uma história clínica e exames físico e neurológico completos para descartar fatores orgânicos que possam estar contribuindo para a sintomatologia psiquiátrica. Recomendam-se os seguintes testes laboratoriais: hemograma completo; níveis plasmáticos de uréia, creatinina, sódio, potássio, cloro, cálcio, dióxido de carbono e fosfato; e testes de função hepática. Um eletrocardiograma (ECG) basal deve ser obtido antes da administração de antidepressivos tricíclicos e lítio, pois estes podem causar alterações cardiológicas. O eletroencefalograma (EEG) também está indicado em casos selecionados (pacientes com epilepsia ou de alto risco para epilepsia) ao se usar antipsicóticos, antidepressivos e lítio, pois estes podem baixar o limiar convulsivo. Testes de função da tireóide são recomendados ao se usar lítio, pois este pode causar hipotireoidismo. Com o uso de tricíclicos, um funcionamento tireóideo anormal prévio pode agravar arritmias cardíacas causadas por estes fármacos.

\section{Considerações especiais quanto à utilização de psicofármacos em crianças e adolescentes}

Kaplan e Sadock (2007) relataram que durante a década de 1990, houve muitos avanços na farmacoterapia de transtornos psiquiátricos na infância, incluindo dados apoiando a eficácia dos inibidores seletivos de recaptação de serotonina (ISRS), no tratamento de transtornos depressivos, transtornos obsessivo-compulsivos e transtornos de ansiedade.

Segundo Maia et al. (2007), os transtornos de ansiedade (TA) são patologias freqüentemente identificadas em crianças e adolescentes, podendo ocasionar prejuízos no funcionamento familiar, social e escolar. Transtorno de pânico (TP), fobias específicas (FE), fobia social (FS), transtorno obsessivo 
compulsivo (TOC), transtorno de estresse póstraumático (TEPT) e transtorno de ansiedade generalizada (TAG) podem ocorrer em todas as faixas etárias. Os TA, em crianças e adolescentes, são, frequentemente, comórbidos e os psicofármacos, em especial os inibidores da recaptação da serotonina (ISRS), são considerados importantes componentes do tratamento destas patologias.

A indicação de psicofármacos para o tratamento de problemas de saúde mental em crianças e adolescentes traz preocupação, mas também esperanças. Preocupação pelo risco dessas indicações tenderem a banalizar o uso como solução imediata e não como um recurso possível a partir da avaliação risco-benefício. Esperança pela possibilidade de novas drogas ajudarem a diminuir graves prejuízos que os transtornos mentais acarretam às crianças e aos adolescentes a curto e a longo prazo.

Segundo Brasil (2000), embora, em grande parte, o emprego de psicofármacos em crianças e adolescentes vise mais os sintomas do que o quadro geral de um transtorno, a escolha da droga deve ser feita a partir de critérios sindrômicos. Ou seja, o tratamento dos transtornos mentais e do comportamento com drogas psicoativas é sintomático e seu uso deve limitar-se ao imprescindível. Na decisão de se usar um psicofármaco, é preciso ponderar se a relação risco-benefício potencial da droga justifica seu emprego e se outros recursos foram devidamente explorados.

O sintoma, ao pertencer a quadros sindrômicos ou categoriais distintos, receberá indicações de tratamento e/ou de psicofármacos de grupos totalmente diferentes. Por exemplo, num paciente o sintoma de "hiperatividade psicomotora" pode estar presente no transtorno de déficit de atenção/hiperatividade (TDAH), num transtorno difuso do desenvolvimento, no retardo mental, em transtornos do humor, em transtornos de ansiedade e em situações reativas ao ambiente.

A autora lembra que alguns transtornos mentais, em crianças e adolescentes, com frequência apresentam comorbidade, o que influencia o plano terapêutico, a evolução e o prognóstico do quadro clínico. Por exemplo, o TDAH tem melhor prognóstico quando não associado ao transtorno de conduta e seu tratamento como quadro único tem muito mais chance de sucesso. Quando em comorbidade a um transtorno depressivo, o planejamento terapêutico precisa levar em conta essa associação.

Segundo Rocha et al. (2004), a farmacocinética lida com o processo biológico que leva a alterações na concentração de drogas nos tecidos e fluidos corporais. As mudanças que ocorrem durante o crescimento na absorção, distribuição, metabolização e excreção de fármacos podem afetar o fornecimento de uma droga ao tecido-alvo. 
Crianças e adolescentes freqüentemente necessitam de doses mais altas por peso do que adultos para conseguir resultados terapêuticos e níveis séricos equivalentes. Isso se atribui a dois fatores: metabolismo mais rápido pelo fígado e filtragem glomerular aumentada.

Estes mesmos autores recomendam que, ao escolher o psicofármaco, deve-e optar por aquele com menor risco de causar efeitos colaterais sérios, resposta prévia do paciente, respostas de familiares àquele medicamento $\mathrm{e}$ experiência do próprio médico com o psicotrópico são fatores importantes. Em relação à posologia, recomenda-se o uso inicial de doses baixas. Com isso, evitam-se doses iniciais que excedam a dose terapêutica para alguns pacientes, abrangendo-se também aquelas crianças e adolescentes que obtêm boa resposta com pequenas doses.

O aumento da dose deve continuar até que um dos seguintes eventos ocorra: a) uma diminuição satisfatória dos sintomas; b) o alcance do limite superior da dosagem recomendada; c) a observação de efeitos colaterais que impossibilitem um aumento da dose; ou d) após uma melhora quantificável dos sintomas-alvo, a ocorrência de um platô na melhora ou uma piora nos sintomas com aumentos adicionais da dose (ROCHA et al. 2004).

No estudo de Maia et al. (2007), as pesquisas com ISRS revelaram maior quantidade de eventos adversos. Isso é importante para que o clínico fique atento aos sintomas de toxicidade quando receitar algum desses psicofármacos. Por exemplo, 88,3\% dos pacientes relataram ao menos um evento adverso com o uso de paroxetina. Os benzodiazepínicos mostraram benefícios pouco expressivos. No ensaio clínico com imipramina, além do número expressivo de comorbidades, houve pouca melhora no grupo tratado. Contudo, os autores afirmaram que os ISRS são, até o momento, os psicofármacos com maior número de ensaios clínicos controlados para TA em crianças e adolescentes. Apresentam resultados modestos quando comparados ao placebo e são liberados pelo FDA apenas para o uso em casos de TOC. A presença de eventos adversos de leves a moderados deve manter o clínico atento durante o período de seguimento. Em termos de implicações clínicas, os referidos autores sugerem que exista espaço para o tratamento farmacológico com os ISRS nos TA em crianças e adolescentes, mas que seu uso deve ser monitorizado com cautela nessa faixa etária.

Segundo Kaplan e Sadock (2007), os tricíclicos quase não foram recomendados desde que os ISRS apareceram no mercado, porque estes têm perfis de efeito adverso mais favoráveis. Fluoxetina, sertralina, paroxetina, fluvoxamina e nefazodona são usadas com relativa frequência para crianças e adolescentes. 
A preocupação em relação aos tricíclicos centraliza-se em seu potencial para cardiotoxicidade, que pode ter contribuído para as mortes subidas de quatro crianças que estavam sendo tratadas com desipramina para transtorno de déficit de atenção/hiperatividae (TDAH). Outros antidepressivos, incluindo bupropiona e venlafaxina, são agentes de segunda linha que costumam ser administrados quando os ISRS não são eficazes.

As drogas antidepressivas são eficazes em muitas formas de depressão, sendo capazes de melhorar notavelmente o humor depressivo sem possuírem ação euforizante sobre a pessoa sadia. Em outras palavras, apresentam uma ação específica sobre os mecanismos fisiopatológicos da depressão.

No tratamento psicofarmacológico, é importante não buscar objetivos gerais, mas específicos, de acordo com o sintoma-alvo. Isso possibilita melhor controle da eficácia da medicação, controle do tempo de tratamento e a individualização do mesmo para cada criança.

Também é importante explicar aos pais ou responsáveis que cada medicação requer um determinado período de tempo para agir e que não se deve interromper abruptamente o uso de determinadas drogas. Como procedimento inicial, queixas somáticas, esteriotipias, maneirismos e tiques devem ser registrados para não serem confundidos, posteriormente, com efeitos colaterais ou adversos (BRASIL,
2000).

\section{As drogas psicoativas mais utilizadas em crianças e adolescentes}

Os antidepressivos são empregados no tratamento de estados depressivos, de caráter endógeno ou biológico, e nos transtornos de ansiedade. $\mathrm{O}$ tratamento começa com doses baixas, com atenção à tolerância inicial do paciente. $\mathrm{O}$ aparecimento dos efeitos antidepressivos pode levar até 4 a 6 semanas, enquanto os efeitos colaterais surgem mais precocemente. A remissão completa dos sintomas pode demorar, não se deve considerar que uma droga tenha atingido sua maior eficácia antes que a dose máxima tenha sido mantida por um período mínimo de quatro semanas(RAMOS; CORDÁS; SALZANO, 2006).

Matos e Souza (2005) salientou que os antidepressivos produzem, em média, uma melhora de $60 \%$ a $70 \%$ dos sintomas depressivos no prazo de um mês. Em termos de eficácia parece não haver diferenças significativas entre as drogas, o que não significa dizer que todos os pacientes responderão aos diferentes antidepressivos da mesma maneira.

Ramos et al. (2006) relataram que a clomipramina, a fluoxetina e a paroxetina têm sido os últimos antidepressivos usados com 
sucesso no tratamento do transtorno obsessivo compulsivo. As doses necessárias costumam ser altas e os efeitos terapêuticos podem surgir até após seis meses de uso.

A clomipramina, de acordo com estes mesmos autores, é indicada no tratamento de TOC em doses iniciais de $25 \mathrm{mg} / \mathrm{kg}$, com aumentos semanais, de acordo com a resposta clínica, até chegar à dose máxima, de $3 \mathrm{mg} / \mathrm{kg}$. A dose máxima em adolescentes é de $250 \mathrm{mg}$ ao dia. O risco maior deste medicamento é a diminuição do limiar convulsivo, sendo este efeito cumulativo.

Rocha et al. (2004) relataram que a imipramina (uma representante dos antidepressivos tricíclicos) tem sua eficácia comprovada no tratamento de depressão maior em crianças, mas nenhum estudo duplo-cego confirmou esses achados. Os estudos com adolescentes também demonstraram uma resposta pobre a esses tratamentos. Outras indicações para o tratamento com os tricíclicos são enurese, transtorno de déficit de atenção/hiperatividade e angústia de separação. As doses iniciais sugeridas para o tratamento de transtorno depressivo maior são de $25 \mathrm{mg}$ à noite, aumentando-se $25 \mathrm{mg}$ a cada 3 dias, de acordo com a resposta clínica ou até se atingir uma dose máxima de $5 \mathrm{mg} / \mathrm{kg} / \mathrm{dia}$.

Já os inibidores da monoamino-oxidase (IMAO) são antidepressivos pouco usados na infância e adolescência porque requerem uma dieta especial sem tiramina. Eles têm efeitos adversos graves e interagem com outros medicamentos, podendo causar crises hipertensivas e convulsões. Entre os alimentos e drogas que devem ser evitados estão queijos, chocolates, comidas defumadas, passas, remédios para resfriados e para asma, estimulantes, cafeína, tricíclicos, etc (ROCHA et al., 2004).

Segundo Matos e Souza (2005), antes de iniciar a terapia com antidepressivos, é necessário investigar a coexistência de distúrbios decorrentes do uso de substâncias bem como outras condições médicas que estão sendo tratadas concomitantemente, para evitar interações medicamentosas indesejáveis. Comorbidade com doenças clínicas, em especial as da tireóide, tem sido frequentemente associada ao quadro depressivo. Este autor relata ainda os efeitos colaterais dos antidepressivos. Segundo ele, a hipomania é uma complicação que atinge de 5 a $20 \%$ dos pacientes deprimidos tratados com antidepressivos. No ganho de peso é induzido, principalmente por antidepressivos tricíclicos, inibidores da monoaminoxidase (MAO) e lítio.

A indução de convulsão pode ser atribuída a alguns antidepressivos - o risco te sido discreto (menor do que $1 \%$ ) e pode se elevar com o aumento da dose. Os antidepressivos tricíclicos, trazodona e inibidores da MAO usualmente provocam 
hipotensão ortostática como principal efeito cardiovascular. Esse efeito indesejável pode ser minimizado com o aumento mais lento da dose.

O distúrbio do sono e a ansiedade podem ser exacerbados por fluoxetina em alguns pacientes, assim como a desipramina e a bupropiona podem aumentar a ansiedade(MATOS; SOUZA, 2005).

Segundo Rocha et al. (2004), o uso de lítio tanto em crianças quanto em adultos implica cuidados na manutenção de níveis terapêuticos. No caso do uso em crianças devese evitar níveis tóxicos, pois nessa faixa etária há rápido metabolismo e riscos aumentados de desidratação, especialmente em crianças hiperativas. Os principais efeitos colaterais incluem náuseas, vômitos, aumento de peso, cefaléias e tremores. Os níveis séricos devem ser monitorados com cuidado, para evitar toxicidade, e deve-se estar atento para o desenvolvimento de hipotireoidismo e leucocitos.

Estes autores relataram que, quando se usa a carbamazepina é frequente a ocorrência de tonturas, diplopia e náuseas no início do tratamento. E, que o ácido valpróico pode causar sedação e efeitos gastrointestinais, que são menores na forma de divalproato sódico. Também podem ocorrer ganho de peso e hepatotoxicidade. Deve-se atentar para a possibilidade de desenvolvimento de ovários policísticos em meninas.
Segundo Kaplan e Sadock (2007), os antagonistas de opióides endógenos, como a naltrexona, e os ISRS, como a fluoxetina, têm sido prescritos na tentativa de diminuir comportamento autodestrutivo em pacientes com retardo mental. Quando TDAH coexiste com esta condição, o metilfenidato tende a ser efetivo.

As doses iniciais de Cloridrato de fluoxetina sugeridas para crianças são de 5 a 10 mg, utilizando-se a forma líquida para melhor dosagem. A dose terapêutica tende a ser entre 10 e $20 \mathrm{mg}$, administrada pela manhã, para evitar insônia. Nos adolescentes, inicia-se com uma dose matinal de $10 \mathrm{mg}$, aumentando para $20 \mathrm{mg}$ em 1 a 2 semanas. As doses para o tratamento de transtorno obsessivo-compulsivo (TOC) em adolescentes podem ser aumentadas até $80 \mathrm{mg}$, divididas em duas tomadas se não houver resposta terapêutica em mais de 5 semanas. As doses recomendadas para bulimia são de $60 \mathrm{mg}$ ao dia. Os principais efeitos colaterais incluem inapetência, perda de peso, náusea, aumento de ansiedade, insônia e agitação (ROCHA et al., 2004).

Antidepressivos podem ser tentados para crianças com TDAH que são resistentes a estimulantes e aquelas com transtornos de tique preexistentes. Bupropiona é tentada quando os estimulantes são ineficazes no tratamento de TDAH. A desipramina tem sido um pouco efetiva, mas seu uso é limitado devido aos 
riscos associados. Outros tricíclicos, hoje pouco recomendados, incluindo a nortriptilina e a clomipramina, foram tentados com algum sucesso

(ROTHENBERGER;

BANASCHEWSKI, 2005).

Antipsicóticos "atípicos" mais recentes - antagonistas de serotonina-dopamina (ADSs) - como a risperidona, a olanzapina, a clozapina e a ziprasidona permitiram que uma variação mais ampla de pacientes resistentes se beneficiasse de tratamento com neurolépticos. Acredita-se que os ASDs aliviem tanto os sintomas positivos como os negativos de esquizofrenia e produzam menos risco de efeitos adversos extrapiramidais e menos potencial para o desenvolvimento de discinesia tardia (ROCHA et al., 2004).

No tocante aos antagonistas dos receptores $\beta$-adrenérgicos, Kaplan e Sadock (2007) relataram que estes reduziram a agressividade em estudos não-controlados de adultos e crianças com retardo mental. Lítico e anticonvulsivantes, como carbamazepina, também podem ser tentados. Os antipsicóticos têm a vantagem de início de ação rápido e pouca necessidade de monitoração laboratorial de seus efeitos adversos, mas o uso de outros fármacos elimina o risco de discinesia tardia.

Estes autores salientaram, também, que o metilfenidato é indicado nos transtornos de aprendizagem, mas sem outro transtorno mental, pois facilita o desempenho em diversos testes cognitivos, psicolingüísticos, de memória e vigilância padronizados, mas não melhora as avaliações de desempenho acadêmico ou avaliações do professor.

Esse mesmo agente (metilfenidato) é o mais pesquisado no tratamento de TDAH. A dextroanfetamina tem eficácia comparável e, ao contrário do metilfenidato é aprovada pela Food and Drug Administration (FDA) para crianças a partir dos 3 anos de idade; a idade inicial para o metilfenidato é de 6 ano (ROTHENBERGER; BANASCHEWSKI, 2005).

Kaplan e Sadock (2007) relataram que o haloperidol, em dosagens não-sedativas revelou-se eficaz na redução de acessos de raiva, agressividade, estereotipias, comportamento autodestrutivo, hiperatividade e retraimento em crianças com transtorno autista. Este mesmo antipsicótico, assim como a pimozida são os medicamentos mais efetivos para o transtorno de Tourette. $\mathrm{O}$ uso de estimulantes como a clonidina reduz tiques tanto no TDAH em crianças e adolescentes como nos casos co-mórbidos.

Maia et al. (2007) relataram que os ISRS foram estudados no transtorno autista, quando pesquisadores postularam uma associação entre os comportamentos compulsivos no tratamento obsessivocompulsivo e comportamentos estereotipados comuns em crianças com autismo. Até o 
momento, a clomipramina e a fluoxetina revelaram-se promissoras para acabar com estereotipias e outros comportamentos em pessoas autistas.

A eficácia de medicações como alprazolam e clonazepam pode ser claramente comprovada no tratamento de sintomas somáticos e sinais autonômicos de ansiedade (palpitações, tremores, sudorese) encontrados em diferentes transtornos de ansiedade, como pânico, por exemplo (ROCHA et al., 2004).

Kaplan e Sadock (2007) recomendam a utilização destes agentes (benzodiazepínicos) assim como dos tricíclicos em casos de terror noturno e de sonambulismo. Segundo estes autores, estes agentes atuam reduzindo tanto o sono de onda delta como despertares entre os estágios de sono. De acordo com os autores: doses terapêuticas de cloridrato de sertralina (entre 25 e $200 \mathrm{mg} /$ dia) são recomendadas para o tratamento de TOC, transtorno de pânico e transtorno pós-traumático; doses de $20 \mathrm{mg}$ de cloridrato de paroxetina é indicada para casos de depressão e fobia social. Enquanto que as doses de 40mg são utilizadas para o tratamento de TOC e transtorno de pânico. A clonidina (um estimulante) é efetiva quando o transtorno de conduta está associado ao TDAH e quando a agressividade é leve.

Os benzodiazepínicos podem também controlar a ansiedade proveniente de situações circunscritas específicas que a criança ou o adolescente possam ter que enfrentar, denominada,ansiedade antecipatória, relacionada a episódios potencialmente geradores de medo e ansiedade, como no caso de procedimentos médicos (ROCHA et al., 2004).

\section{Combinações medicamentosas}

Segundo Mari et al. (2005), o tratamento com combinações medicamentosas é por vezes utilizado para se atingir a melhor resposta no tratamento dos transtornos mentais. As razões incluem falta de resposta, resposta parcial, demora no início da resposta, intolerância aos efeitos adversos e presença de transtornos co-mórbidos.

As estratégias de combinação, segundo Kaplan e Sadock (2007) podem envolvem dois ou mais agentes com a mesma indicação terapêutica. Em alguns casos, pode haver uso simultâneo de duas classes diferentes de antidepressivos (por exemplo, um inibidor seletivo da recaptação de serotonina (ISRS) e a bupropiona (Wellbutrin). Outras estratégias consistem no acréscimo de um segundo agente com uma indicação não-relacionada, como hormônio da tireóide associado a um antidepressivo.

Alguns medicamentos são utilizados quase exclusivamente com papel auxiliar. Os antiparkinsonianos, por exemplo, costumam ser 
prescritos por psiquiatras para tratar os efeitos adversos extrapiramidais dos antagonistas dos receptores de dopamina. A co-administração de agonistas de benzodiazepínicos pode melhorar o resultado do tratamento ao aumentar os efeitos do agente principal ou auxiliar a manejar sintomas particulares, como a ansiedade ou a insônia, que acompanham a maioria dos transtornos psiquiátricos.

No entanto, os referidos autores lembram que cada agente adicional aumenta a possibilidade de interações adversas. Além disso, passa a mensagem que a pessoa em tratamento pode interpretar - por vezes de fora correta - como o desespero. Em termos de adesão, quanto mais medicamentos são utilizados, mais relutante pode ficar o paciente em continuar o tratamento.

As principais considerações ao utilizar a potencialização de medicamentos incluem o potencial para o aumento da resposta e os riscos possíveis. É prudente informar o paciente dos riscos e benefícios envolvidos nas combinações medicamentosas e documentar com clareza as razões para utilizar essa estratégia.

Segundo Brasil (2000), o uso concomitante de vários psicotrópicos, seja para potencializar efeitos, pela presença de comorbidades ou de outras condições médicas associadas, tem sido frequente. $\mathrm{O}$ maior conhecimento do metabolismo dos psicotrópicos tem fornecido dados mais consistentes sobre interações medicamentosas, principalmente das drogas metabolizadas por isoenzimas do citocromo P450 (CYPs). Tais fatos têm gerado preocupação tanto pela possibilidade de diminuírem a ação das drogas envolvidas, quanto pelo potencial de causarem toxicidade.

De acordo com Oliveira (2009), muitos pacientes com transtorno bipolar podem não ficar estáveis com um único estabilizador de humor. O tratamento em combinação é, assim, comum no manejo dessa condução. Em geral, os pacientes tomam um estabilizador principal do humor, como o lítio, a carbamazepina (Tegretol) ou o divalproato (Depakote), ou uma combinação destes. Como acréscimo, um antagonista dos receptores de dopamina, um ASD ou o clonazepam (Rivotril) podem ser utilizados ao mesmo tempo, em particular durante o tratamento de mania aguda. Os pacientes com transtorno bipolar na fase depressiva também podem ser tratados com um antidepressivo.

Segundo Brasil (2000), em crianças e adolescentes, a associação de psicofármacos entre si ou com medicamentos para problemas clínicos (p. ex. acne, candidíase, problemas de vias aéreas superiores, entre outros) requer cautela. Benzodiazepínicos (alprazolam ou clonazepan), quando associados à eritromicina oral (usada em infecções cutâneas) ou ao cetoconazol oral (medicação usada na 
candidíase ou outras infecções micóticas), têm seus metabolismos alterados, pois a eritromicina e o cetoconazol são dois potentes inibidores do CYP3A. O lorazepam não é metabolizado via CYP e deve ser a opção de escolha nessas situações. A claritromicina, antibiótico usado no tratamento de infecções de vias aéreas superiores e de outros tipos de infecções, é um potente inibidor do CYP3A e, se usado com determinados neurolépticos (risperidona, pimozide, haloperidol), pode leválos a níveis tóxicos.

Rocha et al. (2007) relataram que os estabilizadores do humor são medicações usadas em psiquiatria da infância e adolescência habitualmente da mesma forma que são usadas em adultos, ou seja, a sua maior indicação é o tratamento do transtorno de humor bipolar. Por outro lado, sintomas como descontrole de impulsos e agressividade, presentes em uma variedade de outros quadros, podem também ser controlados com drogas como lítio, carbamazepina e ácido valpróico. Essas medicações podem ser usadas para o tratamento do transtorno, não havendo diferenças estatisticamente significativas no efeito das drogas quando comparadas entre si. Há, no entanto, clara descrição na literatura da necessidade de, em muitos casos, associar-se mais do que um estabilizador para o controle da ciclagem e de episódios maníacos.

Os cuidados com os estabilizadores do humor em crianças e adolescentes seguem os parâmetros de controle usados em adultos, devendo-se monitorizar os níveis séricos das drogas e realizar hemograma com contagem de plaquetas para o controle de eventuais leucopenias com carbamazepina. O ganho de peso excessivo pode ser um problema com o uso de ácido valpróico, assim como efeitos gastrointestinais no início do tratamento.

Para Brasil (2000), os tratamentos devem ser mistos, envolvendo intervenções farmacológicas, psicoterápicas e psicossociais, na maioria dos transtornos mentais na infância e adolescência. Portanto, o uso da medicação não deve constituir "o tratamento da criança" mas sim fazer parte de um plano mais amplo em que outros tipos de intervenções também sejam incluídas.

\section{Psicanálise versus Psicofarmacologia}

Segundo Pimentel (2008), a psicanálise atua no sentido contrário dos psicofármacos. $\mathrm{O}$ que não significa que ela desconsidere a utilidade e eficácia destes.. $\mathrm{Na}$ verdade a psicanálise visa não somente a supressão dos sintomas, mas também pensar o papel que este sintoma desempenha na organização psíquica do sujeito. Para o uso de medicação basta uma queixa, algo que cause sofrimento e o desejo de livrar-se desta dor. Isto acontece porque os psicofármacos possuem um ideal de eficácia: 
eliminar os sintomas e qualquer fator individual que altere este resultado deve ser desconsiderado. Em contrapartida, para a psicanálise é necessário que haja também um desejo de saber sobre o sintoma. A autora acredita que existe uma articulação da psicanálise associada com a terapia medicamentosa. A função do psicofármaco no contexto analítico não buscaria a redução dos sintomas ou adaptação social, mas propiciar calma ou ânimo suficiente para o paciente, possibilitando a fala, permitindo que a análise possa prosseguir, permitindo melhores condições para a elaboração dos conflitos.

Kaplan e Sadock (2007) relataram que a psicoterapia com crianças e adolescentes em geral é mais direta e ativa do que costuma ser com adultos. As crianças não conseguem, muitas vezes, sintetizar as histórias de suas próprias vidas, mas são excelentes relatores de seus estados internos atuais. Este tipo de tratamento é indicado para crianças com transtornos emocionais que parecem ser permanentes o suficiente a ponto de impedirem o amadurecimento e o desenvolvimento. Além disso, pode ser indicada quando seu desenvolvimento não está atrasado, mas induzindo reações no ambiente que são consideradas patogênicas.

De acordo com estes autores, o transtorno de déficit de atenção/hiperatividade tem sido estudado de forma mais sistemática em relação a combinações de psicoterapia e medicação. Psicoestimulantes, como metilfenidato e dextroanfetamina, quando combinados com terapia comportamental ou cognitivo-comportamental, são mais efetivos para melhorar o comportamento social e desempenho acadêmico.

Segundo Antônio et al. (2006), nenhum estudo de tratamento psicoterapêutico e medicação combinados de transtornos do humor, transtornos de ansiedade ou esquizofrenia em adolescentes foi publicado, mas estudos em pacientes adultos, como aqueles com transtorno depressivo maior, transtorno obsessivo-compulsivo e esquizofrenia sugerem que psicoterapia combinada com medicação tem maior eficiência para reduzir os sintomas.

Avanços no desenvolvimento de fármacos ampliaram a escolha dos medicamentos para tratar transtornos de humor (ISRS) e esquizofrenia (ASDs, incluindo risperidona, olanzapina e clozapina). Ainda que esses medicamentos tenham sido usados para tratar transtornos do adolescente, uma pesquisa sistemática é necessária para determinar a eficácia e os perfis de segurança de tais agentes no tratamento de psicopatologia adolescente (MAIA; ROHDE, 2007).

As intervenções psicoterápicas podem ser de diferentes formatos, como psicoterapia de apoio, psicodinâmica breve, terapia 
interpessoal, terapia comportamental, terapia cognitiva comportamental de grupo, de casais e de família (MATOS; SOUZA, 2005).

A abordagem psicodinâmica presume que os eventos da história e os aspectos do desenvolvimento da personalidade interagem para causar os problemas psicológicos atuais de um paciente. Alguns pesquisadores indicam que as experiências de vida são a influência estatisticamente mais importante em relação aos escores de depressão (WAJNSZTEJN, 2006).

A abordagem comportamental focalizase em como o comportamento das pessoas (especificamente as habilidades sociais) atinge a sua capacidade de receber reforço positivo vindo do ambiente. Como o reforço aumenta a frequência mensurável do comportamento, a incapacidade que uma pessoa tem de receber reforço para um comportamento saudável afeta diretamente os sintomas depressivos (TOLMAN, 2009).

Atividades prazerosas podem servir como reforçador na elevação do humor, mas, para as pessoas deprimidas, geralmente faltam às habilidades sociais necessárias para tais atividades ou falta pelo menos a capacidade de manifestar tais habilidades quando estão deprimidas. Portanto, o objetivo principal da terapia comportamental é aumentar a quantidade de atividades prazerosas, bem como as interações que elevam o humor.
As considerações do tratamento centralizam-se no conceito de que as pessoas deprimidas podem aprender a melhorar suas habilidades sociais e a aumentar a sua participação em atividades agradáveis. Quando as pessoas começam a experimentar um aumento nas atividades agradáveis e quando sua habilidade para se relacionar bem com os outros resulta em crescente reforço social para os comportamentos não-depressivos, sua depressão melhora (TOLMAN, 2009).

Portanto, segundo Tolman (2009), o tratamento comportamental geralmente consiste de:

- definir uma lista de eventos agradáveis para o paciente $\mathrm{e}$ pedir que aumente o número de eventos agradáveis que realiza diariamente - isso geralmente implica que os pacientes façam um registro diário das suas atividades, juntamente com uma escala de satisfação com as atividades, variando de 1 a 10.

- pedir ao paciente que faça o acompanhamento do seu humor, fazendo um diário de como se sente durante os eventos e também no início 
e no final do dia - este

exercício ajuda o paciente e

o clínico a conhecerem a

relação entre o humor no

início do dia, durante as

atividades e no final do dia.

$\mathrm{O}$ diário do humor serve

como base para a

intervenção, com técnicas

que ajudam a aumentar as

habilidades, os reforçadores

e, consequentemente, o

humor;

- realizar um treinamento de habilidades sociais, assertividade, resolução de problemas e relaxamento o treinamento nessas áreas pode ajudar os pacientes a construírem

relacionamentos e a se sentirem mais no controle, a tomarem decisões e a se acalmarem;

- utilizar o ensaio dos comportamentos e o role playing - fazer com que os pacientes ensaiem e representem novos comportamentos durante a sessão de terapia frequentemente se revela uma abordagem de tratamento eficaz. Essas técnicas permitem que os pacientes pratiquem novos comportamentos e recebam um feedback direto do clínico. Clinico e paciente podem, então, discutir e trabalhar antecipadamente os empecilhos ao sucesso do uso dos novos comportamentos.

- Praticar a terapia de exposição - o clinico acompanha o paciente até um ambiente típico de uma situação social temida. As técnicas praticadas durante as sessões de terapia podem então ser praticadas no ambiente real. Isso permite que o paciente aperfeiçoe novas habilidades e solucione problemas no contexto de uma situação segura.

O uso da terapia comportamental, terapia familiar, treinamento de habilidades sociais e treinamento parental constitui um 1039 
Lembrando que TDAH não é um problema de aprendizado como a dislexia e a disortografia, mas dificuldades em manter a atenção, associada à desorganização e a inquietude que atrapalham bastante o rendimento dos estudos (MALUF, 2010).

As teorias cognitivo-comportamentais concentram-se em como os pensamentos, as imagens e o sistema de crenças internos da pessoa afetam o seu comportamento. Apesar de existirem várias teorias cognitivas diferentes, os métodos de tratamento tendem a incorporar estratégias comportamentais devido à interação entre cognições e comportamento (TOLMAN, 2009).

Segundo Lima (2004) é recomendável a utilização da terapia cognitivo-comportamental com a criança e a família, treinamento de necessidades sociais (semelhante à terapia cognitivo-comportamental, com grande enfoque em atividades abertas e desenvolvimento de habilidades específicas), psicoterapia interpessoal, com foco no relacionamento, e terapia familiar(LIMA, 2004).

Os clínicos cognitivo-comportamentais concentram-se na identificação, na testagem objetiva e na correção dos padrões de pensamento distorcido e dos esquemas subjacentes. Utilizando-se os elementos ativos da terapia cognitivo comportamental associados à mudança, uma abordagem de tratamento típica incluiria, segundo Tolman (2009):
- Terapia como colaboração ativa - desde o inicio do tratamento o clinico enfatiza a colaboração ativa e envolve o paciente na definição da pauta das sessões. Pergunta explicitamente ao paciente quais as questões mais urgentes e pede que compartilhe a visão do clinico do que poderia ser alcançado na sessão.

- Educar os pacientes sobre a abordagem de tratamento - o clínico educa o paciente a respeito da relação sobre eventos, pensamentos, sentimentos e comportamento, enfatizando que os eventos (por si só) não determinam a reação emocional, mas que são os pensamentos sobre os eventos que lhes dão um significado.

- Criar habilidades para testar as hipóteses - o clinico examina primeiro as crenças específicas que causam sofrimento emocional (por exemplo: não consigo fazer nada certo), e então, testando diretamente essas hipóteses (por exemplo: pedir que o paciente faça listas do que fez de errado e certo 
durante as últimas três semanas)

e pedindo que o paciente avalie os dados.

- Aumentar a percepção das distorções de pensamento ajuda o paciente a reconhecer as distorções de pensamento. Como por exemplo: em resposta a uma afirmação como "sempre fui um fracasso total", o clinico poderia perguntar: "você fracassou em tudo ou houve algumas áreas em que realmente pode ter se saído bem?" ou "Houve vezes em que algumas falhas foram piores do que outras?"

- Atacar os esquemas - o clinico deve ajudar os pacientes a procurar informações contraditórias ao conteúdo dos esquemas negativos e a tirar conclusões mais específicas para a situação em vez de conclusões gerais.

- Designar uma tarefa de casa dar ao paciente uma tarefa de casa para se focalizar nos alvos terapêuticos, como, por exemplo, documentar: eventos ativadores que desencadeiam certas crenças; sentimentos que se relacionam a crenças particulares; alternativas para as crenças irracionais, dentre outras.

Em muitos aspectos, a psicoterapia de grupo é um ambiente natural para adolescentes. A maioria deles fica mais à vontade com iguais do que com adultos. O grupo diminui a sensação de poder desigual entre o terapeuta adulto e o paciente adolescente. A participação varia, dependendo do desembaraço. Nem todas as interpretações as interpretações e confrontações devem vir do terapeuta, que representa o pai; membros do grupo muitas vezes são capazes de perceber comportamento sintomático uns nos outros, e os adolescentes podem achar mais fácil ouvir e considerar comentários críticos ou desafiadores vindos de seus pares (KAPLAN; SADOCK, 2007).

Segundo Matos e Souza (2005), a psicoterapia de grupo em geral trata de problemas de vida interpessoais e correntes. Entretanto, alguns adolescentes são muito frágeis para psicoterapia de grupo ou têm sintomas ou traços sociais com muita probabilidade de evocar zombaria do grupo; eles necessitam de terapia individual para obter força de ego suficiente para lutar contra esses aspectos. Ao contrário, outros devem resolver problemas interpessoais em um grupo antes de 
poderem lidar com questões intrapsíquicas na intensidade de terapia individual.

\section{DISCUSSÃO}

Segundo Lima (2004), a depressão infantil e o transtorno bipolar estão associados a fatores genéticos, temperamento, eventos adversos da vida, divórcio, problemas acadêmicos, abuso físico e sexual e fatores neurobiológicos. São transtornos importantes, muitas vezes de difícil diagnóstico, que, uma vez reconhecidos e tratados, irão minorar o sofrimento de crianças e adolescentes.

$\mathrm{O}$ transtorno depressivo em crianças e adolescentes é um quadro clínico grave, crônico e recorrente e que tem como uma das consequiências mais desoladoras as tentativas de suicídio (REIS; FIGUEIRA, 2002). Já o transtorno obsessivo em crianças e adolescentes propicia o surgimento de tentativas de suicídio, que podem variar desde as de pouca gravidade até aquelas que culminam com a morte.

É preciso conhecer os psicofármacos, assim como os demais procedimentos terapêuticos que têm demonstrado ou vêm demonstrando sua eficácia relativa e seus riscos e efeitos secundários (BRASIL, 2000; KAPLAN; SADOCK, 2007).

Os efeitos adversos relacionados a antidepressivos diminuíram de forma significativa desde que os ISRS foram aceitos como tratamentos de primeira linha para transtornos depressivos em crianças e adolescentes.

Os tricíclicos são raramente recomendados devido aos riscos acentuados de efeitos adversos perigosos, os quais são semelhantes àqueles para adultos e resultam das propriedades anticolinérgicas dos fármacos. As consequencias mais graves são cardiovasculares; em crianças, hipertensão diastólica é mais comum, e hipotensão postural ocorre com menos frequência do que em adultos.

Os inibidores seletivos de recaptação da serotonina (ISRS) são atualmente os antidepressivos mais utilizados nessa faixa etária, e essa tendência relaciona-se ao perfil de efeitos colaterais mais seguro, com redução da cardiotoxicidade e menor risco de letalidade com superdosagem (KAPLAN; SADOCK, 2007; ROCHA; BATISTA; NUNES, 2009).

Os ISRS também são utilizados no tratamento da anorexia nervosa, quando os sintomas-alvo são obsessões e compulsões e altos níveis de ansiedade e sintomas depressivo (KAPLAN; SADOCK, 2007; MAIA; ROHDE, 2007). Fluoxetina, sertralina, paroxetina, fluvoxamina e nefazodona são usadas com relativa frequência para crianças e adolescentes (BRASIL, 2000; KAPLAN; SADOCK, 2007). Caetano (2009) relatou que as drogas mais utilizadas são antidepressivos, como 
sertralina e fluoxetina, que já foram testados cientificamente para uso infantil. Eles atuam na regulação da serotonina, a substância responsável pela sensação de bem-estar e satisfação. O remédio é ministrado por cerca de seis meses com acompanhamento médico.

Antagonistas de serotonina-dopamina (ASDs) são recomendados como agentes de primeira linha no tratamento de transtornos psicóticos em crianças e adolescentes (ROCHA; BATIST; NUNES, 2004; KAPLAN; SADOCK, 2007).

Os ASDs em geral substituíram os antipsicóticos convencionais como agentes de primeira linha no tratamento de todos os transtornos psicóticos em crianças e adolescentes. Historicamente, os antipsicóticos melhor estudados administrados a grupos de idade pediátrica são a clorpromazina e o haloperidol.

Maia et al. (2007) sugeriram que exista espaço para o tratamento farmacológico com os ISRS nos TA em crianças e adolescentes, mas que seu uso deve ser monitorizado com cautela nessa faixa etária. De acordo com Rocha et al. (2004); Kaplan e Sadock (2007), o uso combinado do lítio com o divalproato de sódio parece ser mais eficaz no tratamento do transtorno bipolar nessa faixa etária, já que apenas a metade dos pacientes respondem à monoterapia em fase aguda.

Deve-se ficar atento à falta de resposta ao tratamento e a que TA na infância pode cronificar ou evoluir para outras psicopatologias (MAIA; ROHDE, 2007). Sendo os psicofármacos substâncias que alteram o estado de consciência e o funcionamento neuroquímico do cérebro, e observando a ascensão meteórica da sua utilização, é necessário implantar uma intervenção com resultados comprovados: a psicoterapia (BRASIL, 2000; MATOS; SOUZA, 2005; ROTHENBERGER; BANASCHEWSKI,2005; $\quad$ KAPLAN; SADOCK, 2007; BEZERRA, 2008).

O tratamento dos transtornos do uso de substâncias psicoativas envolve psicoterapia, educação familiar e alguns fármacos, por vezes necessitando internação hospitalar (MATOS; SOUZA, 2005; KAPLAN; SADOCK, 2007).O tratamento dos transtornos do humor envolve o uso de fármacos (antidepressivos), associados a psicoterapia (MARI; RAZZOUK; PERES; DEL PORTO, 2005; MATOS; SOUZA, 2005; KAPLAN; SADOCK, 2007). A Ritalina é um dos medicamentos mais utilizados no tratamento do TDAH. À base de metilfenidato, atua como estimulante do sistema nervoso central e regulariza a função do neurotransmissor dopamina

(ROTHENBERGER;

BANASCHEWSKI, 2005).

No caso da bulimia, cuidados médicos especializados e tratamento psicológico são 
essenciais (MATOS; SOUZA, 2005).

O tratamento dos transtornos de conduta envolve basicamente psicoterapia, podendo-se utilizar alguns fármacos no controle da impulsividade desses pacientes. São transtornos de difícil manejo, e muitas vezes necessitam de intervenções familiares e sociais (BRASIL, 2000; MATOS; SOUZA, 2005).

O desenvolvimento de uma intervenção psicoterapêutica para determinada criança inclui avaliação da idade, nível de desenvolvimento, tipo de problema e estilo de comunicação. Seja qual for o estilo ou a combinação de técnicas que o terapeuta escolhe usar na psicoterapia, o relacionamento entre este e a criança é um elemento essencial.

\section{CONSIDERAÇÕES FINAIS}

Observamos que:

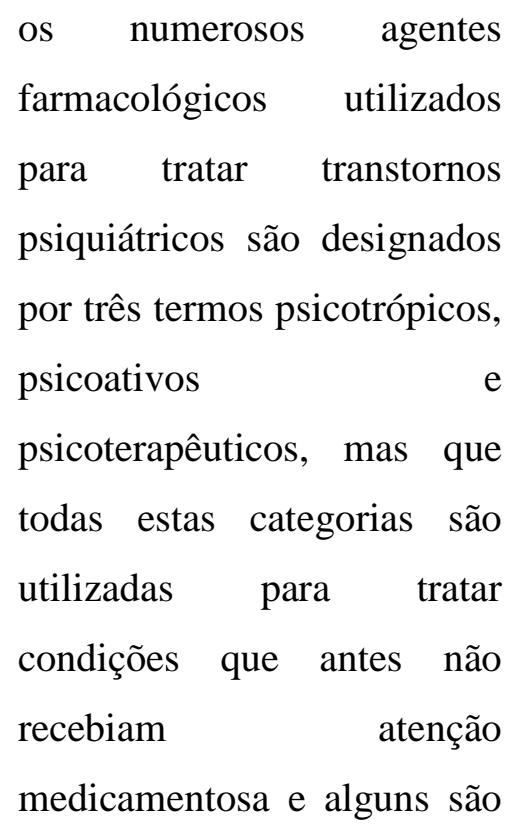

utilizados para uma série de transtornos. Portanto, o profissional da área de saúde deve entender a categoria farmacológica de cada medicamento, suas indicações, contraindicações, interações medicamentosas e efeitos adversos.

Em relação às diretrizes clínicas que devem ser utilizadas na escolha do medicamento evitando os fracassos terapêuticos, concluiu-se que a escolha e o início da intervenção medicamentosa devem ser baseados na história do paciente, na situação clínica atual e no plano de tratamento.

Sobre o tratamento terapêutico com psicofármacos em pacientes infantis e adolescentes, concluiu-se que: o emprego de psicofármacos em crianças e adolescentes deve visar $\quad 0 \quad$ quadro sintomatológico e sindrômico. Ou seja, o 
sintoma, ao pertencer a categoriais distintas, receberá indicações de tratamento e/ou de psicofármacos de grupos totalmente diferentes. $\mathrm{Na}$ decisão de se usar um psicofármaco, é preciso ponderar se a relação riscobenefício potencial da droga justifica seu emprego e se outros recursos foram devidamente explorados.

As drogas psicoativas mais utilizadas em crianças e adolescentes são: A clomipramina, a fluoxetina e a paroxetina (transtorno obsessivo compulsivo); Os inibidores da monoaminooxidase (IMAO) são antidepressivos pouco usados na infância e adolescência porque requerem uma dieta especial sem tiramina; fluoxetina (distúrbio do sono e ansiedade); metilfenidato, Bupropiona e desipramina (TDAH); haloperidol (redução de acessos de raiva, agressividade, estereotipias, comportamento autodestrutivo, hiperatividade e retraimento em crianças com transtorno autista).

Em crianças e adolescentes, a associação de psicofármacos entre si ou com medicamentos para problemas clínicos requer cautela. Benzodiazepínicos (alprazolam ou clonazepan), quando associados à eritromicina oral (usada em infecções cutâneas) ou ao cetoconazol oral (candidíase ou infecções micóticas), têm seus metabolismos alterados. E sobre outras formas de tratamento psiquiátrico, concluiu-se que: a psicoterapia com crianças e adolescentes em geral é mais direta e ativa do que costuma ser com adultos.

\section{REFERÊNCIAS BIBLIOGRÁFICAS}

1. ANDRIOLA, W. B., CAVALCANTE, L. R. Avaliação da depressão infantil em alunos da pré escola. Psicologia: Reflexão e Crítica, v.12,n.2, p. 419 428, 1999. 
2. APA (Associação Americana de

Psiquiatria). Manual Diagnóstico e

Estatístico de Transtornos Mentais

(DSM-IV). Porto Alegre. Artes

Médicas, 1994.

3. BATISTA, Marcos Antônio;

OLIVEIRA, Sandra Maria da Silva

Sales. Sintomas de ansiedade mais

comuns em adolescentes. Psic, v.6, n.2,

São Paulo, dez. 2005

4. BEZERRA, Maria Lúcia Maranhão.

Psicofarmacologia e psicoterapia: mitos, benefícios e interferências. In:

ENCONTRO PARANAENSE, CONGRESSO BRASILEIRO, CONVENÇÃO BRASIL/LATINO-

AMÉRICA, XIII, VIII, II, 2008. Anais.

Curitiba: Centro Reichiano, 2008. CD-

ROM. [ISBN - 978-85-87691-13-2].

Disponível em:

www.centroreichiano.com.br. Acesso

em: 23 out. 2010.

5. BIRD, H.R.; DUARTE, C.S. Dados epidemiológicos em psiquiatria infantil: orientando políticas de saúde mental.

Rev. Bras. Psiquiatr v. 24, n.4, p. 1623, 2002 .

6. BRASIL, Heloisa Helena. Princípios gerais do emprego de psicofármacos.
Rev. Bras. Psiquiatr. São Paulo, v.22,

s.2, Dec. 2000

7. CAETANO, Sheila Cavalcante. Tristeza sem fim. Revista COOP, São Paulo, v.29, n.317, março 2009.

8. CANDIANI, Márcio. Uso de Psicofármacos em Crianças e

Adolescentes. 2009. Disponível em: http://marciocandiani.site.med.br/index. asp?PageName=Uso-20de-20PsicofE1rmacos. Acesso em: 22 out. 2010.

9. CÂNDIDA, T. O drama da depressão infantil. Disponível em: http://saude.terra.com.br/interna/0,OI12 4091-EI1507,00.html, 2005. Acesso em: 2 nov. 2010.

10. DEL PORTO, José Alberto; VERSIANI, Márcio. Transtorno bipolar: tratando o episódio agudo e planejando a manutenção.J. bras. psiquiatr v.54, n.2, p. 84-88, abr.-jun. 2005.

11. GALVÃO, Ana Luiza; ABUCHAIM, Claudio Moojen. Transtornos mentais na adolescência. ABC da Saúde, 2001. Disponível em: < http://www.abcdasaude.com.br/artigo.p hp?424>. Acesso em 24 out. 2010. 
12. GIANCATERINO, Roberto. Depressão

infantil: estratégias de intervenção psicopedagógicas em sala de aula com crianças depressivas. 2008. Disponível em:

$<\mathrm{http} / / / \mathrm{www}$. meuartigo.brasilescola.co m/educacao/depressao-infantilestrategias-intervencaopsicopedagogica-.htm>. Acesso em 25 out. 2010.

13. KAPLAN, Harold I.; SADOCK, Benjamin J. Compêndio de

Psiquiatria: Ciências do Comportamento e Psiquiatria Clínica. Porto Alegre: Artmed, 2007.

14. LEITE, E. P. Depressão infantil, 2002. Disponível in: http://www.psicopedagogia.com.br/opin iao/opiniao.asp?entrID=43. Acesso em 25 out. 2010.

15. LIGA DE NEUROCIRURGIA. SISTEMA NERVOSO.COM. Transtorno de déficit de atenção Hiperatividade, 2005. Disponível em: $<$ http://www.sistemanervoso.com/pagin a.php?secao $=12 \&$ materia_id $=254 \&$ mate riaver=1>, acesso em 25out. 2010.

16. LIMA, Dênio. Depressão e doença bipolar na infância e adolescência.
Jornal de Pediatria, Rio de Janeiro, n.80, Suplemento 2 (S11-S20), 2004.

17. MAIA, Carlos Renato Moreira; ROHDE, Luis Augusto. Psicofármacos para o tratamento de transtornos de ansiedade em crianças e adolescentes: uma revisão sistemática. Rev Bras Psiquiatr.v.29, n.1, p. 72-9, 2007.

18. MALUF, Maria Irene. Agitação ou TDAH? Educacional: A Internet na Educação, 2005. Disponível em $<$ http://www.educacional.com.br/entrevi stas/entrevista0126B.asp>, acesso em 3 nov. 2010.

19. MARI, J.J.; RAZZOUK, D.; PERES, M.F.T.; DEL PORTO, J.A. Guia de psiquiatria. Série guias de medicina ambulatorial e hospitalar. Barueri/SP: Manole, 2005.

20. MATOS e SOUZA, F. G. Tratamento da Depressão. In: MARI, J.J.; RAZZOUK, D.; PERES, M.F.T.; DEL PORTO, J.A. Guia de psiquiatria.

Série guias de medicina ambulatorial e hospitalar. Barueri/SP: Manole, 2005. Cap. 5.

21. MENEZES, Tathiana Tavares; MELO, Victor J. O pediatra e a percepção dos 
transtornos mentais na infância e adolescência. Revista Adolescência e

Saúde. v.7, n.3, p. 38-46, jul-set, 2010.

22. MORA, Estela. Psicopedagogia

infanto-adolescente. Guia de orientação para pais e educadores. São

Paulo: Cultural S.A., 2004.

23. OLIVEIRA, Licia Milena de.

Principais temas em Psiquiatria para residência médica. São Paulo:

Medicel, 2009.

24. PAULON, Wagner. Jovens versus problemas emocionais versus fobias.

Net Saber artigos, 2008. Disponível em: <

http://artigos.netsaber.com.br/resumo_ar tigo_27642/artigo_sobre_jovens_versus _problemas_emocionais_versus_fobias >. Acesso em 24 out. 2010.

25. PIMENTEL, Fernanda. A clínica psicanalitica e o uso de psicofármacos, 2008. Disponível em: < http://viafreud.blogspot.com/2008/02/cl nica-psicanalitica-e-o-uso-de.html>. Acesso em 24 out. 2010.

26. PSICANÁLISE. Depressão, uma doença que derruba. 2010. Disponível em: < http://www.psicanalise.psc.br/depressao .htm>. Acesso em: 24 out. 2010.

27. RAMOS, R.T.; CORDÁS, T.A.; SALZANO, F.T. Tratamentos biológicos em psiquiatria. In: ABREU, C.N. (Org.). Síndromes psiquiátricas: diagnóstico e entrevista para profissionais de saúde mental. Porto Alegre: Artmed, 2006. Cap. 25.

28. REIS, Regina Lúcia Ribeiro; FIGUEIRA, Ivan Luiz de Vasconcellos. Transtorno depressivo e suicídio na infância e adolescência. Revista Pediatria Moderna, São Paulo, v.38, n.6, p.215-246, junho de 2002

29. ROCHA, G.P.; BATISTA, B.H.; NUNES, M.L. Orientações ao pediatra sobre o manejo das drogas psicoativas e antiepilépticas. J Pediatr, Rio de Janeiro, v.80, 2 Supl::S45-55, 2004.

30. ROTHENBERGER, Ariebert; BANASCHEWSKI, Tobias. Mentes Inquietas. Revista Viver Cérebro e Mente, $\mathrm{n}^{\mathrm{o}}$ 144, pp.45-55, Jan, 2005.

31. SILVA, Reginaldo da. Inquieto ou hiperativo? Revista Nova Escola, Brasília: v. 18, n. 162, p. 16-16, maio2003. 
32. TOLMAN, Anton. Depressão em

adultos. 3.ed. Porto Alegre: Artmed, 2009.

33. WAJNSZTEJN, Alessandra B.

Caturani. Dificuldade de atenção e hiperatividade: uma realidade presente na sala de aula. CRIAR, Revista de

Educação Infantil, ano 2, n. 8, março/abril, 2006. pp. 8-12.

34. WELLER, Elizabeth B.; WELLER, Ronald A. Artigo: Transtornos depressivos em crianças e adolescentes. In: GARFINKEL, Barry D.; CARLSON, Gabrielle A.; WELLER, Elizabeth B. Infância e adolescência. Porto Alegre: Artes Médicas, 1992.

Capítulo I. p.15-29. 